\title{
Multiple pulmonary nodules in a male with psoriatic arthritis
}

A 64-yr-old male with a longstanding history of psoriatic arthritis presented with a 6-week history of dry cough without other respiratory symptoms. His other past medical history showed hypertension and type II diabetes mellitus. He took methotrexate $12.5 \mathrm{mg}$ weekly (commenced 9 yrs previously), folic acid, aspirin, nortriptyline, metformin, valsartan and insulin. The patient was an ex-smoker of 5 pack-yrs, having stopped smoking 32 yrs earlier. He kept no pets and there was no significant occupational exposure or travel history. On examination his chest was clear. There was no lymphadenopathy or clubbing.

A chest radiograph (fig. 1) showed multiple pulmonary nodules. C-reactive protein was $6 \mathrm{mg} \cdot \mathrm{L}^{-1}$, erythrocyte sedimentation rate was $17 \mathrm{~mm} \cdot \mathrm{h}^{-1}$ and white blood cell count was $13 \times 10^{9}$ cells $\cdot \mathrm{L}^{-1}$. Other routine blood tests were unremarkable and treatment with methotrexate was stopped. Further investigation showed normal tumour markers. Antinuclear antibody and antinuclear cytoplasmic antibody were negative, as was rheumatoid factor. Spirometry was normal. A chest/ abdomen and pelvis computed tomography showed multiple pulmonary soft tissue nodules (fig. 2). There were no other abnormalities. Infarcted tissue with some viable lung parenchyma showing mild chronic inflammation was obtained from a percutaneous needle biopsy of a soft tissue nodule. There were no granulomas or dysplastic or malignant cells. All viral serology testing was normal. Due to the patient being

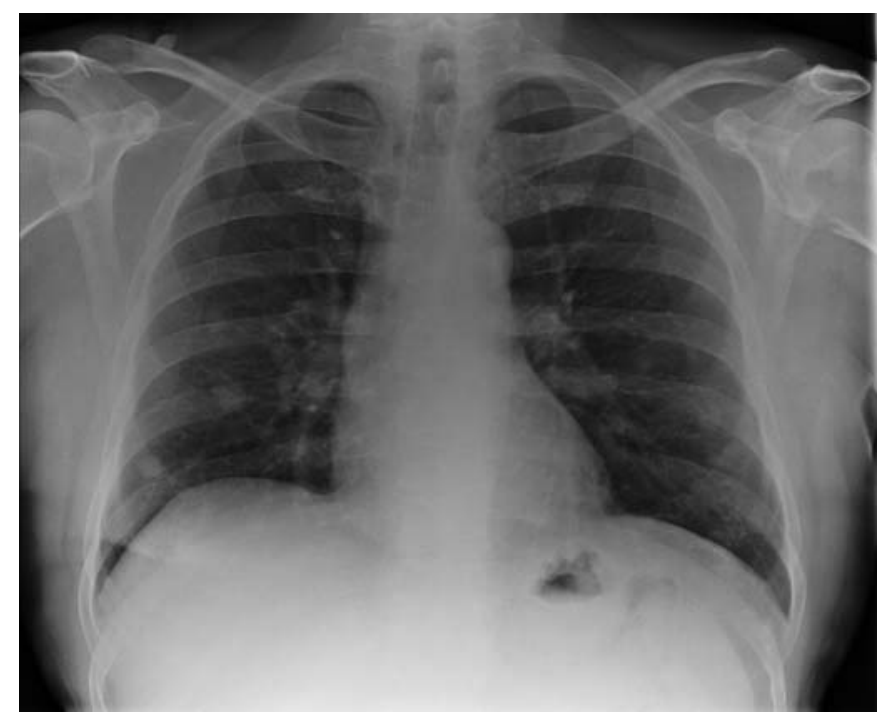

FIGURE 1. Chest radiograph showing nodulosis prior to cessation of methotrexate completely asymptomatic bronchoalveolar lavage was not performed.

Following review of the biopsy a chest radiograph was performed which showed partial resolution of the nodules. A radiograph performed 3 months later showed complete resolution.

The patient received no specific therapy. He remained well and his cough resolved. However, his psoriatic arthritis worsened and he was started on sulphasalazine.

We believe that methotrexate nodulosis is the most likely cause of the pulmonary nodules seen in our patient.

The differential diagnosis of multiple pulmonary nodules is vast and includes infection, malignancy, granulomatous diseases, autoimmune diseases, rheumatoid nodules and drug reactions. A causal relationship between methotrexate and the nodules is supported by a number of factors. First, the nodules resolved spontaneously after methotrexate was stopped. Secondly, there was no histological evidence of malignancy or granulomatous disease. Finally, there was no evidence of either infection or rheumatoid arthritis.

Methotrexate nodulosis is an unusual adverse effect of lowdose methotrexate in patients with rheumatoid arthritis. In this condition methotrexate triggers or accelerates the formation of nodules which are clinically and histologically indistinguishable from rheumatoid nodules [1]. The nodules usually occur on the fingers, elbows or joints. More rarely

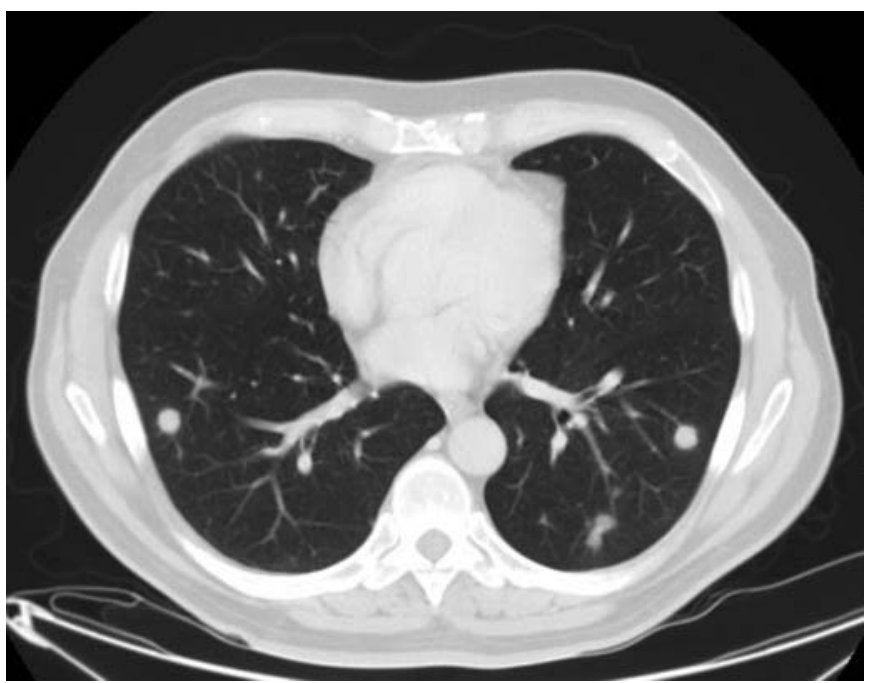

FIGURE 2. Computed tomography scan showing nodulosis prior to cessation of methotrexate. 
they can appear in the lung, heart, larynx and Achilles tendon [2]. Methotrexate nodulosis is rare in patients with rheumatoid arthritis who are negative for rheumatoid factor [3]. Nodules often, but not always, regress or disappear on discontinuing the drug [3].

Methotrexate nodulosis in conditions other than rheumatoid arthritis is very rare. It has been reported in a patient with systemic lupus erythematosus and Jaccoud's arthropathy [4], a patient with juvenile arthritis who was rheumatoid factor negative [5], and a patient with psoriatic arthritis and negative rheumatoid factor [6]. Only the patient with juvenile arthritis had pulmonary nodules. However, a recent case report describes a patient similar to ours with psoriatic arthritis and negative rheumatoid factor who developed accelerated pulmonary nodulosis and a sterile pleural effusion after treatment with methotrexate [7]. Open lung biopsy showed histology compatible with a rheumatoid nodule. The nodules resolved on stopping methotrexate treatment.

\author{
A. Manuel ${ }^{*}$, Q. Jones ${ }^{\#}$ and J. Wiggins ${ }^{\#}$ \\ *Churchill Hospital, Oxford, and "Heatherwood and Wexham \\ Park Hospital, Slough, UK.
}

Correspondence: A. Manuel, Churchill Hospital, Old Road, Headington, Oxford, OX3 7LJ, UK. E-mail: arimanuel1979@ yahoo.co.uk
Statement of Interest: None declared.

Provenance: Submitted article, peer reviewed.

\section{REFERENCES}

1 Di Francesco L, Miller F, Greenwald RA. Detailed immunohistologic evaluation of a methotrexate-induced nodule. Arch Pathol Lab Med 1994; 118: 1223-1225.

2 Kremer JM, Lee JK. The safety and efficacy of the use of methotrexate in long-term therapy for rheumatoid arthritis. Arthritis Rheum 1986; 29: 822-831.

3 Patatanian E, Thompson DF. A review of methotrexate-induced accelerated nodulosis. Pharmacotherapy 2002; 22: 1157-1162.

4 Rivero MG, Salvatore AJ, Gomez-Puerta JA, et al. Accelerated nodulosis during methotrexate therapy in a patient with systemic lupus erythematosus and Jaccoud's arthropathy. Rheumatology 2004; 43: 1587-1588.

5 Falcini F, Taccetti G, Ermini M, et al. Methotrexate-associated appearance and rapid progression of rheumatoid nodules in systemiconset juvenile rheumatoid arthritis. Arthritis Rheum 1997; 40: 175-178.

6 Berris B, Houpt JB, Tenenbaum J. Accelerated nodulosis in a patient with psoriasis and arthritis during treatment with methotrexate. J Rheumatol 1995; 22: 2359-2360.

7 Balbir-Gurman A, Guralnik L. Accelerated pulmonary nodulosis and sterile pleural effusion in a patient with psoriatic arthropathy during methotrexate therapy: a case report. J Clin Rheumatol 2009; 15: 29-30.

DOI: $10.1183 / 09059180.00001210$

\section{Talcosis due to abundant use of cosmetic talcum powder}

\section{To the Editor:}

A 36-yr-old, nonsmoking, Hindustan female presented with complaints of dyspnoea without coughing which had persisted for several months. The complaints started after a bout of pneumonia a few months previously. Her medical history was unremarkable. She did not suffer from asthma, nor did asthma run in the family. She worked at an administrative office. Physical examination showed no abnormalities; in particular, the auscultation of the lungs was normal. A screening laboratory examination, including complete blood count, renal function and liver function tests, was normal. A chest radiograph showed nodular lesions in both lungs (fig. 1a).

Because of the abnormal chest radiograph, a second patient history was carried out and revealed a remarkable twice daily bathing ritual where she used large amounts of cosmetic talcum powder. After bathing the patient powdered her whole body with talcum powder, a ritual she had carried out since her childhood. Ancillary laboratory investigations including angiotensin converting enzyme, total immunoglobulin E and anti-cyclic citrullinated peptide were all negative. A high-resolution computed tomography (CT) scan of the thorax showed a diffuse nodular image in both lungs. Interlobular septa and pleura showed a normal pattern (fig. 1b). Pulmonary function tests showed a restrictive pattern, with a normal diffusion capacity. Bronchoscopy did not reveal any endobronchial abnormalities. Bronchoalveolar lavage was negative for mycobacteria and other infectious agents, and no neoplastic cells were found. Inflammatory cell distribution was normal, including a CD4/CD8 ratio of 0.9 (normal $<2.5$ ). Transbronchial lung biopsies showed patchy peribronchiolar fibrosis and an extensive non-caseating granulomatous inflammation with numerous multinucleair giant cells associated with the massive presence of needle-shaped birefringent crystalline material (fig. $2 \mathrm{a}$ and b). Pulmonary vessels showed no abnormalities. No asbestos bodies were observed.

For tissue analysis by energy-dispersive X-ray spectroscopy (EDX), haematoxylin and eosin stained sections of paraffin embedded lung specimens were screened for birefringent crystals. Small areas were chosen from the paraffin blocks, dissected, de-paraffinised and then embedded in Epon according to Luft's procedure (Merck, Darmstadt, Germany). Ultra-thin sections $(200 \mathrm{~nm})$ were cut on an ultra-microtome (Leica Microsystems, Wetzlar, Germany) and examined in a 